\title{
Innovative Teaching and Technology Integration: Exploring Elderly Teachers' Attitudes
}

\author{
Bazila Tariq \\ M.Phil Scholar \\ Department of Education, UMT \\ Maria Dilawar \\ M.Phil Scholar \\ Department of Education, UMT \\ Dr. Yaar Muhammad \\ Assistant Professor \\ Department of Education, UMT
}

\begin{abstract}
To stay current in this dynamic age, innovation and adaptability is not only considered a key to success, rather it is deemed a significant tool of survival. The field of education has metamorphosed with the shift of focus from teachers' teaching to students' learning. This change implies that teachers consistently update their practices and innovate in order to meet the needs of students with diverse skills. With the introduction of student-centred classrooms, project based learning, practical discovery and technological integration, the traditional lecture methods and the idea of passive students is becoming obsolete. However, the attitude of teachers towards innovation varies. The aim of this study was to explore attitudes of elderly teachers towards innovative teaching strategies. This study used qualitative phenomenological study method and criterion sampling technique to select four participants aged 45 years and above. Data were gathered through a self-constructed semi structured interview guide containing three dimensions. Phenomenological data analysis of these three dimensions showed the presence of some cognitive, behavioural and affective resistance to change among teachers. Therefore, it is suggested that certain aspects of training and guidance need to be provided to elderly teachers in order to make the process of innovation easy to adopt.
\end{abstract}

Keywords: Resistance, Teaching Methods, Innovation, Perceptions, Elderly teachers

\section{Introduction}

'Innovation' is a term that has been used frequently for many years and this single word encapsulates the exciting challenges and changes expected in every field to achieve success. Bringing innovation is about trying out different ideas and adopting new ways of accomplishing goals; an approach of taking risks and stepping into a realm of unexplored possibilities. In the field of education, innovation can be described as the introduction of new policies and procedures, bringing reforms to the syllabus or restructuring the organization with an aim to improve the teaching and learning process. 
The world today is undergoing a continuous change process and it is essential for everyone to keep up with the demands of the new world. For teachers, keeping pace with innovative ideas by transforming their practices is of prime importance as only through innovative learning can we produce a generation of individuals equipped with the skills necessary to survive in the $21^{\text {st }}$ century. Therefore, in order to create a rich learning experience for students and a gratifying teaching experience for educators, continuous growth and adoption of novel ideas is imperative (Subramani \& Iyappan, 2018).

Teachers are an important and dynamic part of the increasingly complex and modern school system. The role of the teacher has been diversified into a facilitator, moderator, mentor, disciplinarian, club manager and planner. In many countries, the innovations in the field of education during the recent years have impacted the job description of teachers (Öztürk, 2011).Teachers need to be equipped with the high level of professional knowledge and should have skills to make decisions when faced with professional challenges. Integrating technology in teaching, providing hands-on learning experiences, creating a conducive classroom environment that encourages free flow of ideas, planning lessons centered on problem based learning, using a variety of assessment methods and catering to students' cognitive, emotional and behavioral needs is the job of today's teacher. However, when expected to adopt all these roles, a varied attitude is often observed with some teachers taking on the challenge head-on while others resisting the change completely. This resistance can have a number of reasons such as denial, nostalgia for the traditional practices, fear of the change process and difficulty in giving up a habit, especially in teachers during the later years of their career(Snyder, 2017; Zimmerman, 2006).

Keeping in view the importance of innovation and the different perspectives teachers have towards it, this paper aims to investigate the challenges faced by elderly science teachers in integrating technology in the lesson and creating student-centered classrooms while exploring their perceptions of adopting innovative teaching methods with a focus on the cognitive, affective and behavioral dimensions of resistance.

\section{Literature Review}

In the world of today, change is the only constant and successful exploitation of new ideas is a key to survival. Only those able to bring about innovation can adapt and evolve as per 
the demands of the changing dynamics of time. One can define innovation as an application not just of novel practices, ideas and knowledge but rather of practices, ideas and knowledge that are improved and enhanced (Mitchell, Clayton, Hedberg, \& Paine, 2003)to fit to the current needs. It can also be defined as a process that is directed towards the achievement of sustainable outcomes that bring about an improvement in what people do and the procedures they adopt to do it(Weiss \& Legrand, 2011). An instrument of essential and positive change (Serdyukov, 2017), innovation is an applied creativity (Weiss \& Legrand, 2011) that facilitates the process of competing and excelling in every area of work.

The field of education has also been revolutionized with a focus on student centered classrooms and activity based learning. In educational context, innovation is imperative as education is central to creating a sustainable future (Serdyukov, 2017). Over the past few decades there has been a shift in the pedagogical approach to classroom teaching with teachers adopting innovative teaching methods such as simulations, role-plays, problem-based learning and portfolio development (Subramani \& Iyappan, 2018)over the traditional lecture method. Such learner centered classrooms actively involve students in the process of learning acquisition by giving them charge of their learning processes, involving them in the process of decision making and maximizing the classroom time allocated for interactive activities among learners (Nunan, 2004).

One important aspect of innovative teaching is information and communications technology (ICT) integration. Technology integration not only leads to developing a better understanding of the basic concepts (Ranasinghe \& Leisher, 2009)but also fosters group collaboration skills (Gorakhnath \& Padmanabhan, 2017). It also serves as a tool for teaching problem solving skills and developing critical thinking through a visual representation of real life situations(McKenzie, 1999).Therefore, computer literacy of teachers is a need of the hour and it is essential for teachers to be tech-savvy in order to bring an innovation to the teaching and learning process. It is a common observation that young teachers, particularly the ones who have recently graduated are more aware of the benefits of incorporating technology in the classroom; however, older teachers face a challenge in this regard (Ranasinghe \& Leisher, 2009). This difficulty might also occur due to external reasons such as resource management, time for planning, support and training or intrinsic reasons such as the teachers' approach, beliefs and practices regarding their traditional method of teaching (Earle, 2002). 
A number of studies have been conducted to show the benefits of innovative teaching methods in students' achievement. A study conducted by Vajravelu and Muhs (2016) indicated that students had a more steady experience related to content and assessment in an innovated course rather than the same course taught in a traditional format and a significantly higher success rate was recorded for the redesigned lesson in comparison to the traditional methodology. However, there is a varied perspective of teachers while adopting these methods of creating student centered classrooms, using multiple forms of assessment or integrating technology in education. For some teachers, looking beyond their current practices and developing novel ideas to do things in a new way is considered imperative to ensure learning and to cater to individual needs of students (Serdyukov, 2017); however, for some adopting change is a challenge. This resistance on part of some teachers stems from a feeling of being burdened or conflicted by the change process (Evans, 2001).

Bringing about innovation to one's existing practices disrupts the framework by which individuals make sense of their lives so the natural disposition is to resist. Habit is also identified as a barrier to adopting novelty (Zimmerman, 2006). Therefore, age can be considered a factor impacting the openness to change as habits strengthen with time and it is convenient to carry on with the same ways rather than developing new sets of skills and strategies. Innovation requires assimilating new ideas into a pre-existing network and this process is often slow due to cognitive, behavioral and affective resistance as it aims to postpone, alter or stop the proposed change (Kadi \& Beytekin, 2014)in order to preserve and maintain the status quo (Ibrahim \& Zaatari, 2013).

There are various factors in play that lead to affective resistance to innovation. Such emotional resistance is based on negative emotions of sadness, contempt and hatred. Individuals exposed to innovative ideas might also direct hostility and anger towards the agents of change due to a feeling of nostalgia and a deep commitment to traditional practices (Ungar \& Nagar, 2014). Other emotions such as a feeling of loss, doubt and discomfort have also been associated with affective resistance to change (Ibrahim \& Zaatari, 2013).

Cognitive structures play a fundamental part in the process of adopting innovation, with some teachers being more willing to adopt change as compared to others. All individuals have constructed a mental model of the world they live in; hence, their perception of the world around 
them differs. These mental maps assist individuals in making sense of their context and help in interpreting the reality (Zimmerman, 2006). These pre-existing mental structures and links often prevent teachers from bridging the gap between the learning requirements of the modern context and their traditional methods of coping with change, often resulting in behavior that is ineffectual (Duffy, 2002). Finding faults and highlighting inefficiency of change, presenting arguments that support the existing practices, raising claims to maintain the current situation and ignoring the information that specifies the need for innovation are some ways in which cognitive resistance is manifested (Ungar \& Nagar, 2014). Behavioral resistance stems from routine seeking (Oreg, 2003) and is characterized by actions taken to negatively influence the change process.

It is an obvious assumption that elderly teachers are fixed in their approach and are always resistant to change; however, this is not always true. They might engage in continuing renewal procedure by identifying and adopting updated strategies throughout their career to remain relevant, they might be a positive focuser who accepts change, but only within the boundary of their classroom, a disenchanted elderly teacher whose past experience of reform results in skepticism, or a negative focuser who might actively undermine change and impede the process of improvement (Hargreaves, 2005; Huberman, 1988). A study conducted by Snyder (2017) also provided evidence that elderly teachers respond to change differently with some displaying enthusiasm and others being critical towards innovation. However, these elderly teachers also admitted adopting and maintaining strategies that they thought well-suited their students' needs.

As adopting innovation can be a challenge for some teachers, the responsibility of making this transition easy lies with the school administration. Various strategies such as creating awareness among teachers about the need to adopt innovation, providing increased opportunities of mutual decision making, ensuring appropriate professional development and coaching(Zimmerman, 2006), utilizing the wisdom of seasoned educators(Snyder, 2017) to make them feel valued and offering constant encouragement can have a positive impact on teachers' views regarding change, ultimately bringing about the much needed improvement. 


\section{Methods and Materials}

\subsection{Methodology}

A phenomenological approach was adopted for this study as the aim of the research was to describe the meaning for several individuals of a phenomenon or concept based on their lived experiences, that is, the phenomenon of adopting innovation (Creswell, 2007).The study describes the experience of a common phenomenon among individuals with the purpose of condensation of these individual experiences into a universal essence by grasping the very nature of the concept or phenomenon (van Manen, 1990). This phenomenological research design enabled the researchers to form a composite description of the essence of 'what' and 'how' a phenomenon was experienced (Moustakas, 1994)by collection of data from individuals who have lived it (Creswell, 2007).

\subsection{Sampling and Recruitment of Participants}

A sample of four individuals aged 45 years and above was selected using the criterion sampling technique, which is a form of sampling that focuses on the identification and selection of information-rich cases (Miles \& Huberman, 1994). Various criterions such as age, years of employment, subject and grade level were used while selecting participants to ensure the collection of heterogeneous data. The interviewers then contacted the participants using personal links in the field, explained the topic and purpose of research, assured the ethical implications of keeping identity anonymous and requested them to take part in the research study. An appointment for the face-to-face interview was set up with the participant who agreed and follow-up questions were asked via telephonic conversation.

\subsection{Data Collection}

Data were gathered through the most widely used method of data collection in qualitative research (Willig, 2008), that is, a self-constructed semi structured interview guide containing three dimensions. The interview guide was based on open-ended questions that provided the researchers with an outline of discussion majorly based on two wide questions (Moustakas, 1994),that is, a description of what the participants have experienced regarding the phenomenon of adopting innovation and the situations that influenced this experience. Other open-ended questions were also asked and followed up by probing questions to uncover the required 
information. All four face-to-face interviews were conducted separately in the workplace settings of the participants. Before starting the interview, the participants were given information regarding the study and were provided with an opportunity of asking questions about it. The interview started with the collection of some basic demographic information. During the interview, the participants were asked to describe their experience of teaching science over the years. They were also inquired about the challenges faced during their teaching career with a focus on integrating technology in teaching and creating student-centered classrooms. The participants also shared their perspective about the importance of innovation, their attitude towards adopting it, the difficulties faced while trying out new ideas and any motivating factors that enabled them to adopt change and innovation effectively. The interviewer also explored the participants' affective, behavioral and cognitive reactions towards newly introduced ideas and practices. The duration of each interview ranged from 60-90 minutes. The interviews were initially recorded and later transcribed. The transcription was cross-checked with the recordings to ensure inclusion of all information. All formats of collected data, that is, the recordings and the transcripts were coded to ensure anonymity of the participants.

\subsection{Analysis}

Phenomenological data analysis procedure was used in an effort to approach lived experiences of elderly teachers with a sense of novelty to produce rich and descriptive data(Anderson \& Spencer, 2002). Significant statements and quotes were identified from the data to establish an understanding of participants' lived experiences regarding the phenomenon. Data were then thematically organized in order to develop clusters of meaning based on similarities of the lived experience common to all transcripts. From this, textural and structural description emerged that provided an account of what the participants experienced while adopting innovative teaching methods and what factors influenced their experience. Two of the participants were approached the second time to validate findings through follow up questions.

\section{4. $\quad$ Findings}

\section{Participant A}

Demographic profile: a 47 years old female teacher, teaching 'Knowledge and Understanding of the World around Us' to Kindergarten for the past 11 years. 
Participant A viewed her teaching tenure as a "long non-stop learning journey full of exciting and challenging experiences." Describing some of her experiences as "exceptional, positive and satisfying," she explained her work issues as well as the struggle faced in the rapidly changing environment; especially that involving integration of technology in the classroom. She also talked about the difficult phases of her teaching career, with a feeling of being overwhelmed at the various roles demanded of a teacher. "A teacher is now considered all in all, one who has to inculcate ethical values along with academics, with minimal results despite a lot of effort." Over the years, she had experienced many changes and innovations in her classroom practices with "technology integration being one of the major changes with a number of rapid transformations that seemed difficult to absorb altogether." While adopting change, she observed that a number of her colleagues survived the innovation and coped up effectively with the situation, while "some who were very unwilling and reluctant to adopt the change have resigned from their jobs as technology has become a permanent part of teaching and learning." Upon inquiring the reason of resistance, participant A stated that these teachers were above fifty years of age and were set in their ways and faced a lot of difficulty in adopting the new approach. Participant A herself acknowledged the importance of transformation; however, she also highlighted the role of the management in its implementation: "Transformation is good but the school management should see the context and scenario to implement." She explained that use of technology has become an integral part of schools as the day starts by marking attendance on an online app, various gadgets such as computers, tablets, EyeRIS, microscope, Beebot etc. are being used during teaching and learning and online mediums of communication such as 'SeeSaw' and Edmodo are frequently used to interact with parents. "These initiatives also promote a paper free culture." She accepted that educational change is important and crucial with this fast changing world as it leads students to develop multiple skills required to meet the standards globally. She further stated that transformation and improvement is necessary as "we are preparing students for the $21^{\text {st }}$ century where the education system is designed differently from the world we have lived in."

Moreover, she acknowledged that this change was not that easy for her at all as she did not even know how to operate a computer but the situation changed after bringing so many gadgets in the classroom. It was a "nightmare" to prepare all the IT resources to conduct an effective lesson in a way: typing lesson plans, making other files on MS Word, maintaining e- 
portfolios, making PowerPoint presentations and browsing for different online links and videos for students. Handling different IT tools was a big challenge in the start for her. With the passage of time she learned to handle the devices but still at some points she lacked and needed help of her peers. She reported that after every passing day the expectations were getting high from the system. She was not expecting any finishing point to this change and transformation. She needed to continue to exist in the system because her own children are studying in the school.

\section{Commentary}

Participant A appears to be reluctant, hesitant and full of fears every time she comes across any new change and transformation in the system. The change in the form of technology integration did not seem like a good step for her in her normal set routine. Although, the change never made her happy and comfortable but she learnt to survive in the system by adopting the change as her children are getting education from the same school. She faced cognitive resistance initially as she was clueless about the use of computers. However, she has gained knowledge to operate a number of gadgets but still requires help in performing certain tasks.

\section{Participant B}

Demographic profile: a 48 years old female teacher, teaching science to grade I and II for the past 20 years.

Participant B has worked at various levels in national as well as international school systems. Starting with preschool, she reflected on her practice which at that time was based on lecture method. Later, the system introduced interactive teaching methodology, one that incorporated the use of visual aids and as for that kind of lessons "a teacher must have creative skills with artistic qualities", the change was difficult for her in terms of time management; "it took me a lot of time to prepare 3D models for my subject." Then technology took over and the idea of IT integration in lessons became quite popular; this change was even a greater challenge: "I put a lot of effort in grasping the concept so that I can survive in the world full of gadgets, but still I can't get it completely may be because of the generation gap." She also said, "There is a big threat for those teachers who have no IT skills or have less knowledge about technology use, as two of my age fellow colleagues were fired because of this IT integrated system." Participant B acknowledged that technology is now a need of the hour in education as IWB boards, tabs and videos make it easy for students to understand and for teachers to explain concepts effectively 
but "still with all this human touch is important." She had a belief in change and explained innovations in education as "you don't go with the old ways, you don't teach with the old methods, so yes a teacher must use those techniques that can prepare her students as per the demands of coming era." Acknowledging the use of technology in helping students to work smartly she also shared her reservation that "it destroys their hand writings and book reading habits."

\section{Commentary}

Participant B, like the case of participant A above, acknowledges that adopting innovation is a need of the time. However, she is not comfortable adopting these changes due to issues of time management and lack of skill that leads to cognitive resistance. Affectively, she seems to respond to these innovations with a fear of not fitting into the system due to generationgap and feels that these changes pose a threat to her job.

\section{Participant C}

Demographic profile: a 47 years old female teacher, teaching science to grade VIII for the past 25 years.

Reflecting on her career of 25 years, Participant $\mathrm{C}$ described her teaching experience as full of happenings. She started her career with a "rigid but more effective teaching method of giving lectures" and gradually moved from books towards the paper free environment; a change that she perceived as a necessary part of success in the new world. The change brought a modification in the curriculum, introducing new material and methodologies and disregarding the older one in order to stay updated; "I think so many new methodologies are just to make the education look appealing, it gives too much power to students." Another change was the use of technology about which she stated that, "we found it a bit more difficult because maybe we are the older generation." It was very difficult in the start and it took a lot of time to get acquainted with the new integrated function "may be because I was not willing to accept this change and tried to avoid it." Although the school provided trainings before introducing IWB boards, Tabs, E-books and teacher reporting systems but grasping new methods of teaching or using new tools for teaching still remains a challenge for her. She reported particularly being "unhappy" about the new mode of communication between the teachers and the administration, that is, the e-mail. Stating her fear regarding e-mail communication, she stated that, "e-mails are used against 
teachers that's why we have to be very careful regarding what we write." While telling about Ebooks she said, "E-books made my life easy, the biggest benefit for me and for my students is that there's no need to carry heavy books all the time, but it's really difficult to maintain the students' concentration as they only know to use that technology as a gadget and not as a source of learning." Sharing an incident of her classroom, she also discovered that students, when left on their will and given freedom to explore the internet, usually access inappropriate material. "After reporting this incident to the IT department solutions to minimize misuse of Tabs was set into place." She believed that these innovations would become obsolete in the coming years so our priorities should change as well:

Now people are changing as they are genetically born IT smart. However, I believe that it is not going to help them to think smart; we have to think of many other new ways of teaching and learning other than IT because this generation is done with it. IT innovations are a thing of the past for them. Believe it or not I have seen a baby of 5-6 months old operating a smart phone. The need of the hour is to create moral values in our students that are being ignored by the schools in the race to be the most updated institute.

\section{Commentary}

Participant $\mathrm{C}$ sees innovation as a necessity for survival. However, she has her own fears regarding its use and faces emotions like being "unhappy" about it. She also believes that these changes and innovations would ultimately become outdated so our focus should be moral development, which is being overlooked. Feeling nostalgia for the lecture method, she thinks that the new methods are just a way to bedazzle the education process. She feels the generation gap and her initial reaction towards IT integration was resistance.

\section{Participant D}

Demographic profile: a 45 years old female teacher, teaching science to grade $\mathrm{V}$ for the past 11 years.

Working at various private institutes as a science expert at the primary level, Participant $\mathrm{D}$ believed that the main philosophy of teaching is the same. With the changing world, strategies were evolving which she found a "good thing." She argued that being a learner aimed at self- 
development, both professionally and personally, one must adopt new strategies and change practices accordingly because "if you don't then you can also lose your position in the institute."

She shared her insight on adopting change and how she found it difficult to adopt innovation, especially, at the initial stages, as "coming out of one's comfort zone requires quite an effort and energy but after spending time and effort to learn these new practices, it is much easier for me to adjust in that." She felt that the time and energy consumed in learning these new skills outweigh its benefits: "It's too time consuming and sometimes it does not give enough benefit to the teaching and learning process." Comparing traditional methods of teaching with today's she felt that there is nothing wrong with the traditional ways, "I mean, we have also been educated through traditional methodology and our learning is not ineffective."

Displaying a positive attitude towards technology integration, she talked how these methodologies make it easier to conduct lessons in the class and captures students' interest. She appreciated the way teachers around the world shared their creative ideas and work practices through technology and at just one click one could learn from their experiences and replicate them in own classes to enhance learning of students. She further explained that whenever new technology is integrated, learning continues. She added that there were a lot of variations in activities due to technology: "It's quite fascinating as technology broadens your mind."

Participant D seemed quite satisfied with the supportive environment provided by her colleagues, especially her age fellows while adopting and integrating new technology in teaching and for other managerial tasks. "Support is what matters; it eases the overwhelming task of change." Moreover, she shared that she did not get any professional training for using different apps and technology. She learned through family and friends instead. At school, management and teachers are using EDMODO software to communicate with parents so a training workshop from school was provided to teachers in this regard. While talking about it, she accepted and said, "In the beginning, it was a bit difficult but now it seems easy and we are doing it." However, she emphasized that schools should provide more support in this regard rather than leaving the teachers to figure out everything on their own: "It's the school who wants to implement change, the least they can do is to train teachers to adapt easily." 


\section{Commentary}

Similar to the other participants of this study, Participant D holds a view that change is necessary for the sake of survival and job security, maintaining a view that traditional methods were equally effective. For her, innovation requires coming out of one's comfort zone and investing a lot of time and energy, one that does not even yield enough benefits. She has her own support system to deal with change and displayed resentment towards the school administration for enforcing innovation without providing formal training.

\section{Discussion and Conclusion}

It is evident from the analysis of the four cases, that, for each one of them, the adoption of innovative teaching practices came with certain challenges and they faced resistance in their own manner. Having a sound understanding of the fact that the world around us is changing, each one held a view that adopting change is necessary for survival and to equip our students with the skills required for the $21^{\text {st }}$ century. One of the prime motivators that forced these participants to adopt change was to ensure job security.

In terms of affective resistance, the major emotions common to all participants are that of fear and nostalgia. Seeing their colleagues either resign or get fired from their jobs, participants seem to have developed a fear for their job security. They are also fearful of becoming obsolete as they realize that the generation gap hinders their performance. Another fear that one of the participants shared was the negative impact of e-mail communication and the fact that they had to remain on guard regarding whatever they put in writing. Nostalgia for traditional practices also surfaced as a factor of affective resistance. Teachers hold a view that old methods of teaching were equally effective; with one participant relating to her own education while another stating new methods to be just a way to ornate the classroom. Despite all innovation and technological advancements, the importance of "human touch" cannot be overlooked and skills such as handwriting and reading should be developed. Although we are aiming to develop a generation equipped with the $21^{\text {st }}$ century skills, we are falling behind in developing a generation that is morally and ethically equipped and that is what tradition taught us. It is imperative that schools realize their true function and focus on personality building as well. Another emotion reported by one of the participants was that of being "unhappy" about the change while another perceiving it as a "threat". 
Cognitive resistance occurred when these participants faced difficulty in assimilating the new methods in their pre-existing mental structures. Learning the use of technology from scratch and developing artistic abilities to design classroom resources was a challenge for these elderly teachers. Presenting justifications for their traditional practices and finding faults with the current educational system are also examples of cognitively resisting the change process.

In terms of behavioral resistance, participants quoted examples of their colleagues who actively resisted the process and resigned from their position rather than changing. The teachers also believe that these newly introduced methods are time consuming and take up most of their energy and effort, sometimes yielding little or no results. The process of change and adopting novelty forces people to come out of their comfort zone and give up habits and the behaviors of a set and contented routine.

The fact that these teachers reported that they "have to" adopt innovation rather than "wanting to" adopt, shows that for them it is an obligation for survival in the system because they might be helpless due to personal reasons, as in the case of participant A who wants her kids to be educated from the same school. Even though the participants reported facing certain challenges and difficulties, all of them at some level agreed that these changes are a need of the hour to stay relevant. They also highlighted the importance of a support system when any change is introduced. Learning from their peers, friends and family; each participant coped with new learning in her own way. However, the participants feel that the school administration needs to play a more effective part in training and development of employees to make the reforms easy to adopt rather than forcing it upon them without clear guidance.

The findings from this research give us some perspective into the trials that elderly teachers face while trying to ensure endurance. These findings can be used by the school administration to make the change process easy for employees by gaining an insight into their emotions regarding it and providing ample training to create an environment where innovation is perceived as a positive step. 


\section{References}

Anderson, E. H., \& Spencer, M. H. (2002). Cognitive representations of AIDS: A phenomenological study. Qualitative health research, 12(10), 1338-1352.

Creswell, J. W. (2007). Qualitative inquiry and research design: Choosing among five approaches. California: Sage publications.

Duffy, F. M. (2002). Step-up-to-excellence: an innovative approach to managing and rewarding performance in school systems. Maryland: Scarecrow Press.

Earle, R. (2002). The integration of instructional technology into public education: promises and challenges. ET Magazine, 42(1), 5-13.

Evans, R. (2001). The human side of school change: reform, resistance, and the real-life problems of innovation. San Francisco: Jossey Bass.

Gorakhnath, I., \& Padmanabhan, J. (2017). Educational robotics: a new arena in classroom teaching. Electronic Interdisciplinary International Research Journal, 6(6), 216-236.

Hargreaves, A. (2005). Educational change takes ages: life, career and generational factors in teachers' emotional responses to educational change. Teaching and teacher Education, 21(8), 967-983.

Huberman, M. (1988). Teacher careers and school improvement. Journal of curriculum studies, 20(2), 119-132.

Ibrahim, A., \& Zaatari, W. E. (2013). Teacher resistance to educational change in the United Arab Emirates. International Journal of Research Studies in Education, 2(3), 25-36.

Kadi, A., \& Beytekin, O. F. (2014). The opinions of teacher candidates about resistance to change and scientific epistemological beliefs. European Journal of Research on Education, 2(6), 178-185.

McKenzie, J. (1999). How teachers learn technology best. Bellingham: FNO Press.

Miles, M. B., \& Huberman, A. M. (1994). Qualitative data analysis: A sourcebook of new methods. Thousand Oaks, California: Sage publications.

Mitchell, J., Clayton, B., Hedberg, J., \& Paine, N. (2003). Emerging futures: innovation in teaching and learning in VET. Melbourne: Australian National Training Authority.

Moustakas, C. (1994). Phenomenological research methods. Thousand Oaks California: Sage Publications.

Nunan, D. (2004). Methodology. In D. Nunan (Ed.), Practical englsih language teaching. Singapore: McGraw-Hill Education.

Oreg, S. (2003). Resistance to change: developing an individual differences measure. Journal of Applied Psychology, 88(4), 680-693.

Öztürk, G. (2011). Public Primary School Teachers' Perceptions of Their Working Conditions and Job Stress: Cases from Istanbul and Stockholm: Institutionen för internationell pedagogik, Stockholms universitet. 
Ranasinghe, A. I., \& Leisher, D. (2009). The benefit of integrating technology into the classroom. International Mathematical Forum, 4(40), 1955-1961.

Serdyukov, P. (2017). Innovation in education: what works, what doesn't, and what to do about it? Journal of Research in Innovative Teaching \& Learning, 10(1), 4-33.

Snyder, R. R. (2017). Resistance to Change among Veteran Teachers: Providing Voice for More Effective Engagement. International Journal of Educational Leadership Preparation, 12(1), 4-17.

Subramani, N., \& Iyappan, V. (2018). Innovative methods of teaching and learning. Journal of Applied and Advanced Research, 3(1), 20-22.

Ungar, O. A., \& Nagar, N. M. (2014). Teachers in a changing world: attitudes toward organizational change. Journal of Computer Education, 1(4), 227-249.

Vajravelu, K., \& Muhs, T. (2016). Integration of digital technology and innovative strategies for learning and teaching large classes: a calculus case study. International Journal of Research in Education and Science, 2(2), 379-395.

van Manen, M. (1990). Researching lived experience: human science for an action sensitive pedagogy. Albany: State University of New York Press.

Weiss, D. S., \& Legrand, C. (2011). Innovative intelligence. Ontario: Wiley \& Sons Canada Ltd.

Willig, C. (2008). Introducing qualitative research in psychology: adventures in theory and method. Buckingham: Open University Press.

Zimmerman, J. (2006). Why some teachers resist change and what principals can do about it. National Association of Secondary School Principals, 90(3), 238-249. 